\title{
Polyethylene microplastics adversely affect airway patency
}

\author{
Nurshafida Adzlin Shamsul Anuar'1, Li-Yin Pang ${ }^{1}$, Sivathass Bannir Selvam², Christopher \\ Gibbins $^{2}$ and Kang-Nee Ting1,* \\ ${ }^{1}$ School of Pharmacy, University of Nottingham Malaysia, Jalan Broga, 43500 Semenyih, Malaysia. \\ ${ }^{2}$ School of Environmental and Geographical Sciences, University of Nottingham Malaysia, Jalan Broga,
} 43500 Semenyih, Malaysia.

*Correspondence: Kang-Nee.Ting@nottingham.edu.my

Received: 14 September 2021; Revised: 2 December 2021; Accepted: 3 December 2021; Published: 8 February 2022

DOI https://doi.org/10.28916/lsmb.6.1.2022.93

\begin{abstract}
Human exposure to microplastics through inhalation has been widely reported in recent years. There is a paucity of work focusing on the direct effect of accumulation of microplastics in airways and how it may impact the respiratory function. This study aimed to investigate whether the exposure of microplastic would change the contractility of isolated airway smooth muscle tissue. Microplastics were obtained through milling of high-density polyethylene (HDPE) pellets by using a centrifugal mill. To confirm that the milled microplastic particle size range fell within the definition of microplastic, field-emission scanning electron microscope (FESEM) was employed. The milled microplastics particle size ranged from $44.2 \mu \mathrm{m}$ to 552.4 $\mu \mathrm{m}$. The organ bath technique was employed to study the direct change of tissue contractility of rat isolated tracheal rings. Tracheal rings were incubated with polyethylene microplastics of different concentrations $(0.3 \mathrm{mg} / \mathrm{ml}$ to $10 \mathrm{mg} / \mathrm{ml})$ for a minimum of 18 hours in physiological Krebs buffer, followed by the construction of concentration-response curves to a contractile agent, carbachol (muscarinic agonist). Exposure to all concentrations of polyethylene microplastics enhanced the contractile responses of the tissues to carbachol. However, the effect was only statistically significant in tissues incubated at $3 \mathrm{mg} / \mathrm{ml}$ and above $(p<0.05)$. Findings from this study provide preliminary evidence that exposure to polyethylene microplastics adversely affects airway function. Heightened contractile responses of airways mimic the pathophysiological responses in respiratory diseases such as asthma, chronic cough and chronic obstructive pulmonary disease. Further experiments focusing on the possible mechanism of actions of these microplastics affecting the airway tissue function are now needed.
\end{abstract}

Keywords: Microplastics; polyethylene; pollution; airway contractility and inhalation

\section{INTRODUCTION}

Microplastic pollution and its potential impacts on the environment and human health have become a topic of considerable discussion in recent years. Microplastic is defined as any insoluble synthetic solid particle with a regular or irregular shape and with a size ranging from $1 \mu \mathrm{m}$ to $5 \mathrm{~mm}$, of either primary or secondary manufacturing origin (Frias \& Nash, 2019). Studies have shown that the human body is exposed to microplastics through three main routes: inhalation of airborne microplastics, ingestion of food or water containing microplastics and dermal contact with plastic-made products or microplastics-containing dust (Prata et al., 2020). An alarming proposition was recently highlighted that existing nonbiodegradable microplastics in the atmosphere will continue to cycle through the earth's systems (Brahney et al., 2021). 
Besides the long-standing concerns about the impacts of plastic waste, the COVID-19 pandemic has resulted in an unprecedented increase in plastic usage due to single-use disposable masks, gloves and protective gowns. An extraordinary rise in the production of disposable face masks made from different types of polymeric nanofibers, including polyethylene, polypropylene, polyurethane, polyacrylonitrile or polystyrene, has been reported (Fadare \& Okoffo, 2020). These have now become a major contributor to the plastic waste problem (Adyel, 2020). In addition, a recent study has demonstrated the risk of microplastics inhalation through face masks (Li et al., 2021). Although the uptake of microplastics in respiratory tissues and its long-term impact on health is not entirely understood, studies have demonstrated the deposition of inhaled particles in airways (Geiser \& Kreyling, 2010; Vianello et al., 2019).

Once inhaled, microplastics can have a direct effect by colliding with the walls of the upper airway (AmatoLourenço et al., 2020). Some particles may then descend into the lower respiratory tract due to gravity (AmatoLourenço et al., 2020). Their fate is highly dependent on particle properties such as size and density, and lung physiology (Prata, 2018). These foreign particles are typically removed from the respiratory tract through several clearance mechanisms that include coughing and sneezing, mucociliary escalator as well as macrophage phagocytosis (Thomas, 2013). However, these defence mechanisms are impaired in people with respiratory conditions such as asthma, chronic obstructive pulmonary disease, and primary ciliary dyskinesia (BustamanteMarin \& Ostrowski, 2017). Due to the degradation-resistant nature of microplastics, their long-term accumulation in the respiratory tract could potentially lead to local inflammation and exacerbation of existing respiratory conditions or other health problems in instances where they are translocated (Pang et al., 2021).

Despite the growing evidence of microplastics exposure through inhalation, data on its functional impact on the airway smooth muscle is lacking. The airway patency is tightly controlled by the autonomic nervous system whereby the major contribution of the contraction of the respiratory tract comes from the activation of the muscarinic receptors on the smooth muscles during the activation of the parasympathetic pathway. Thus, in order to study the possible direct impact of the microplastics on airway tissue function, we used the organ bath system and carbachol, a muscarinic agonist, to stimulate airway tissue contraction.

\section{MATERIALS AND METHODOLOGY}

\section{Polyethylene microplastics preparation and particle size analysis}

Bimodal high-density polyethylene pellets (HDPE, Borstar HE6063, Austria) were gifted by Sinowaja (Malaysia) Sdn. Bhd. (Sarawak, Malaysia). The HDPE pellets were ground using a centrifugal mill (Retsch Ultra Centrifugal Mill ZM200, Restch, USA) at $8000 \mathrm{rpm}$, with a $200 \mu \mathrm{m}$ ring sieve. The ground material was removed from the collecting cassette and filtered further with a $212 \mu \mathrm{m}$ stainless steel sieve.

Particle morphology of the HDPE powder was investigated using a Field Emission Scanning Electron Microscope (FESEM) (FEI Quanta 400F, FEI Company, USA). The FESEM was set with the following parameters: voltage $=10 \mathrm{kV}$, spot size $=3.5$, magnification $=100 \mathrm{x}$, working distance $=10 \mathrm{~mm}$, with large-field detector and low vacuum mode for non-conductive samples. A small amount of the HDPE powder was mounted on the microscope stubs with carbon tape before being inserted into the sample chamber of the FESEM. Then, images displayed on the viewing screen were captured and the diameters of the particles were measured using a measuring tool function available in the FESEM software.

\section{Drug and Krebs-Ringer bicarbonate solution}

Carbamylcholine chloride (carbachol) (Nacalai Tesque, Japan) was dissolved in purified water (purified by ELGA PURELAB® flex water purification system) to make a stock concentration of 0.1 M. The Krebs-Ringer bicarbonate solution was freshly prepared daily using purified water, following the composition (in $\mathrm{mM}$ ): $\mathrm{NaCl}$ $120, \mathrm{KCl} 5.4, \mathrm{MgSO}_{4} .7 \mathrm{H}_{2} \mathrm{O}$ 1.2, $\mathrm{KH}_{2} \mathrm{PO}_{4} 1.2, \mathrm{NaHCO}_{3} 25$, glucose 11.7, $\mathrm{CaCl}_{2}$ 1.26; $\mathrm{pH} 7.4$ and aerated with $95 \% 02$ and $5 \% \mathrm{CO} 2$.

\section{Tissue preparation and experimental protocol}

Ethical approval was obtained from the University of Nottingham's Animal Welfare and Ethics Review Body (AWERB) (Reference: UNMC12). The experiments were conducted with male Sprague-Dawley rats (244 - 591 g; 2 - 3 months old). Animals were purchased from the Faculty of Veterinary Medicine, University Putra Malaysia and sacrificed on the day of the experiment by asphyxiation with carbon dioxide. The trachea was removed and prepared as described in our previous study (Loong et al., 2015). The surrounding connective tissues were removed before excising the trachea into $2 \mathrm{~mm}$ rings.

Then, the trachea rings were transferred into glass scintillation vials filled with different amount of HDPE powder in $5 \mathrm{ml}$ of aerated Krebs solution. The concentration of HDPE microplastics used in this study were 0.3 $\mathrm{mg} / \mathrm{ml}, 1.0 \mathrm{mg} / \mathrm{ml}, 3.0 \mathrm{mg} / \mathrm{ml}, 5.0 \mathrm{mg} / \mathrm{ml}$ and $10.0 \mathrm{mg} / \mathrm{ml}$. These concentrations were achieved by measuring 1.5 $\mathrm{mg}, 5.0 \mathrm{mg}, 15.0 \mathrm{mg}, 25.0 \mathrm{mg}$ and $50.0 \mathrm{mg}$ of HDPE microplastics into the glass scintillation vials and adding $5 \mathrm{ml}$ of aerated Krebs solution into the vials. The tissues were then stored at $4{ }^{\circ} \mathrm{C}$ for 18 hours. Glass scintillation vials 
were used to avoid risk of plastic leaching from plasticwares (Honeycutt et al., 2017).

Following overnight incubation (18 hours), each ring was placed in a glass chamber filled with $10 \mathrm{ml}$ of Krebs solution. The temperature was maintained at $37{ }^{\circ} \mathrm{C}$ and tissues were supplied with $95 \% \mathrm{O}_{2}$ and $5 \% \mathrm{CO}_{2}$ throughout the experiments. Changes in muscle tension were detected by a force transducer (MLTF050/ST, ADInstruments, USA). Data were recorded with a PowerLab data acquisition system (LabChart v7.3.8). After the application of tension of $9.8 \mathrm{mN}$ (equivalent to $1 \mathrm{~g}$ ), tissues were left to equilibrate to bath condition for at least 30 minutes. Next, the tissues were exposed to $60 \mathrm{mM}$ potassium chloride (KCl) two to three times to assess tissue viability. Any tissue with an average $\mathrm{KCl}$-induced tone of $<3.92 \mathrm{mN}$ was considered to be non-responsive (Loong et al., 2015). Subsequently, cumulative concentration-response curves (CRCs) to carbachol ( $0.1 \mathrm{nM}$ to $300 \mu \mathrm{M})$ were constructed at time intervals of 5 minutes or until the response plateaued. The degree of contraction was measured as a fraction of the contraction from basal tension and expressed as a percentage of $60 \mathrm{mM} \mathrm{KCl-induced}$ tone.

\section{Statistical analysis}

The diameter (width) of the polyethylene microplastic particles was measured using the measuring software following the FESEM (FEI Quanta 400F). Data obtained from the organ bath experiments were expressed as mean \pm standard error of mean (SEM) of n number of animals. GraphPad Prism version 8.4.3 for Windows (GraphPad software, USA) was utilised for data analysis and graphical visualisation of the data. The maximum response (Emax) and $\mathrm{pEC}_{50}$ values were derived from non-linear regression analysis of the obtained $\mathrm{CRC}_{\text {. The }} \mathrm{pEC}_{50}$ value is the negative logarithm of $\mathrm{EC}_{50}$ where $\mathrm{EC}_{50}$ is the concentration of drug that produces $50 \%$ of its maximum response. Statistical comparisons of $\mathrm{E}_{\max }$ and $\mathrm{pEC}_{50}$ between the control and HDPE-treated group were performed using unpaired t-test (two-tailed) and the results were considered statistically significant if p-value $<0.05$.

\section{RESULTS}

\section{Particle size distribution of HDPE microplastics}

The shape and size of the milled and sieved microplastics varied, as evident from the FESEM (Figure 1). The particle size ranged from $44.2 \mu \mathrm{m}$ to $552.4 \mu \mathrm{m}$, with more than $70 \%$ of the pieces being smaller than $200 \mu \mathrm{m}$ (Table 1). Some particles appeared round while others were long and irregular. Those with a round shape tended to have smaller diameter than those with irregular dimensions.

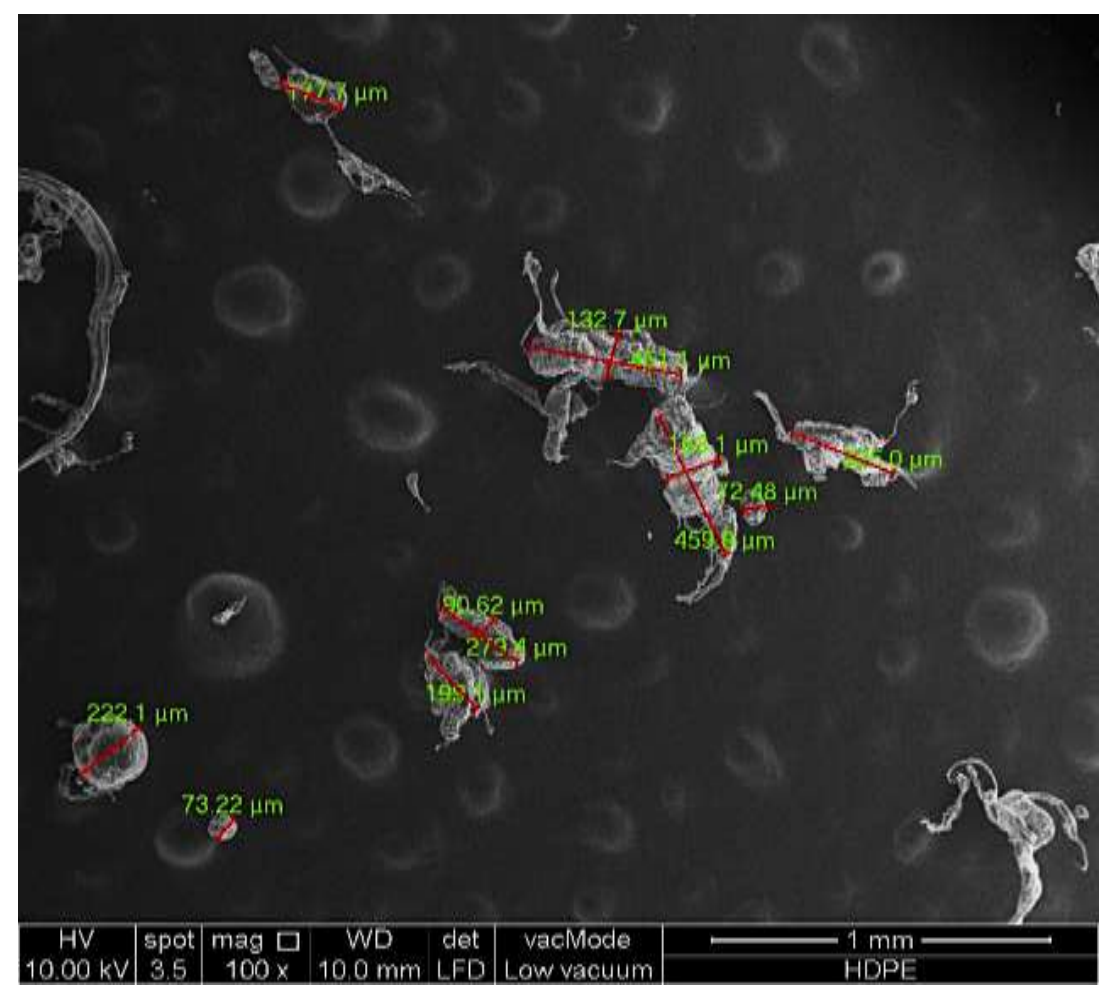

Figure 1: A representative image of the polyethylene microplastics viewed under field emission scanning electron microscope (FESEM). Abbreviations: $\mathrm{HV}=$ voltage, spot = spot size, mag = magnification, $\mathrm{WD}=$ working distance, det $=$ detector, LFD = large-field detector (pre-selected for non-conductive samples), vacMode = vacuum mode, HDPE = high density polyethylene (sample name). 
Table 1: Particle size distribution of the milled and sieved polyethylene microplastics. The FESEM imaging was conducted four times and the particle diameters were grouped into three categories $(1-200 \mu \mathrm{m}, 201-400 \mu \mathrm{m}$ and $401-600 \mu \mathrm{m})$. The mean diameters of the particles were measured with the FESEM measuring software.

\begin{tabular}{lll}
\hline Sample diameter $(\mu \mathrm{m})$ & Mean diameter $(\mu \mathrm{m})$ & Percentage $(\%)$ \\
\hline $1-200$ & 119.5 & 70.00 \\
$201-400$ & 272.5 & 23.33 \\
$401-600$ & 534.3 & 6.67 \\
\hline
\end{tabular}

\section{Polyethylene microplastics potentiated carbachol-induced contractions}

Figure 2 and Table 2 show that at all concentrations of the microplastics tested, airway responses to carbachol were affected. Significant changes were observed in tissues exposed to microplastics at higher concentrations $(3$ $\mathrm{mg} / \mathrm{ml}, 5 \mathrm{mg} / \mathrm{ml}$ and $10 \mathrm{mg} / \mathrm{ml}$ ) whilst a marginal increase in the maximum response to carbachol was detected in the lower concentrations $(0.3 \mathrm{mg} / \mathrm{ml}$ to $1 \mathrm{mg} / \mathrm{ml})$, as compared to the control. $E_{\max }$ and pEC 50 values of carbachol derived from the respective CRC are displayed in Table 2.
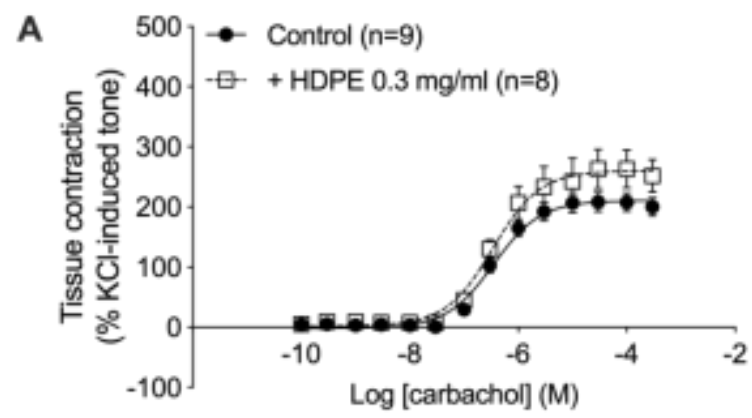

C

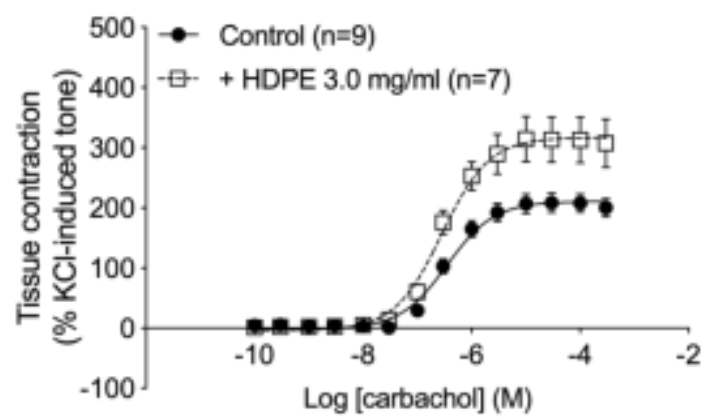

E

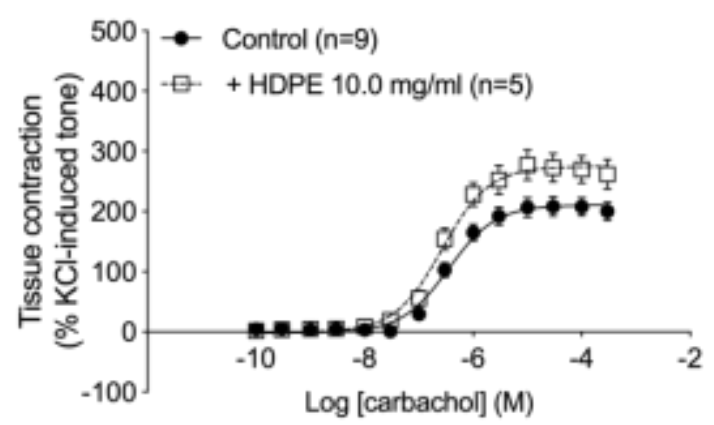

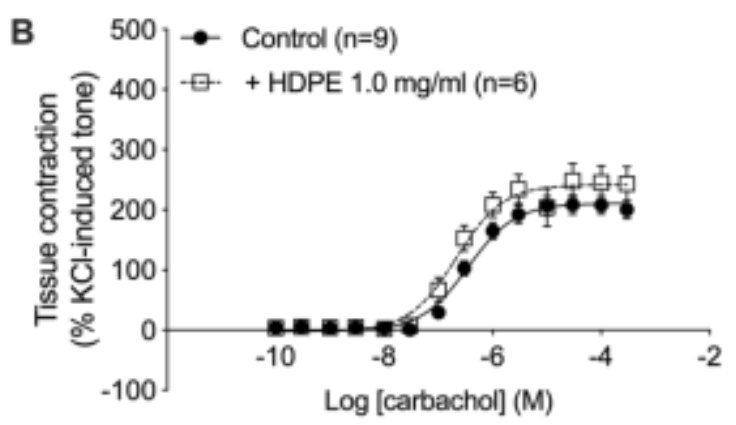

D

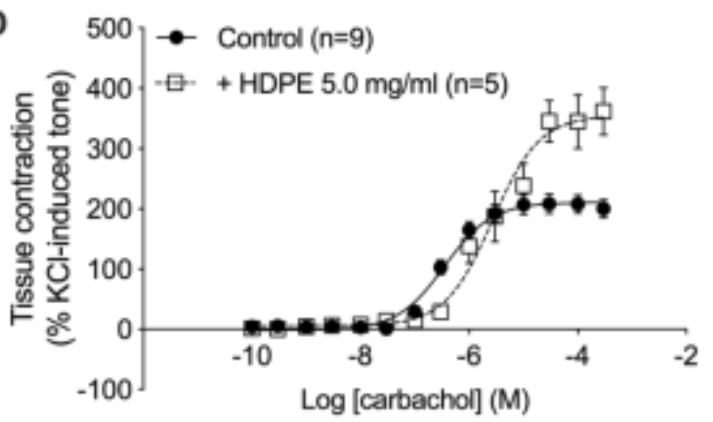

Figure 2: Effect of overnight incubation with high-density polyethylene (HDPE) microplastics on carbacholinduced contractions in isolated rat trachea. Tissues were incubated overnight in Krebs solution (control) or Krebs solution with HDPE microplastics (A) $0.3 \mathrm{mg} / \mathrm{ml}$, (B) $1 \mathrm{mg} / \mathrm{ml}$, (C) $3 \mathrm{mg} / \mathrm{ml}$, (D) $5 \mathrm{mg} / \mathrm{ml}$, (E) $10 \mathrm{mg} / \mathrm{ml}$. Cumulative concentration-response curves to carbachol were constructed following overnight incubation. Tissue contractions were expressed as a percentage of $60 \mathrm{mM} \mathrm{KCl}$-induced tone and shown as mean \pm SEM of $\mathrm{n}$ number of animals. 
Table 2: The maximum response $\left(\mathrm{E}_{\max }\right)$ and $\mathrm{pEC}_{50}$ of carbachol were derived from the respective concentration response curve. Unpaired t-test where comparison of the mean was made between control and the HDPE-treated group; ${ }^{*} p<0.05,{ }^{* *} p<0.01,{ }^{* * *} p<0.001$. Data were shown as mean \pm SEM of $n$ number of animals.

\begin{tabular}{llll}
\hline Concentration of HDPE $(\mathbf{m g} / \mathbf{m l})$ & $\boldsymbol{n}$ & $\mathbf{E}_{\mathbf{m a x}} \mathbf{( \% )}$ & $\mathbf{p E C}_{\mathbf{5 0}}$ \\
\hline Control (Krebs solution without HDPE) & 9 & $211.70 \pm 15.62$ & $6.45 \pm 0.07$ \\
0.3 & 8 & $260.30 \pm 33.15$ & $6.50 \pm 0.06$ \\
1 & 6 & $242.60 \pm 23.35$ & $6.65 \pm 0.09$ \\
3 & 7 & $317.20 \pm 38.66^{*}$ & $6.48 \pm 0.11$ \\
5 & 5 & $376.00 \pm 44.71^{* *}$ & $5.54 \pm 0.24^{* * *}$ \\
10 & 5 & $275.40 \pm 23.87^{*}$ & $6.57 \pm 0.05$ \\
\hline
\end{tabular}

\section{DISCUSSION}

As polyethylene is one of the most abundant types of microplastics in the environment and the second highest contributor of atmospheric non-fibrous microplastics (Wright et al., 2020), it was chosen as the material to investigate in the present study. In order to obtain a consistent and controlled supply of microplastic particles, industrial grade high density polyethylene pellets were ground and milled using a centrifugal mill. The size range of the particles produced in our lab was comparable to those identified in atmospheric fallout $(50 \mu \mathrm{m}-5000 \mu \mathrm{m})$ (Zhang et al., 2020) where more than two-thirds of the microplastics recorded had a diameter below $200 \mu \mathrm{m}$.

After 18 hours of incubation with the polyethylene microplastics, the contractile response of the rat tracheal rings towards carbachol (muscarinic agonist) was exaggerated. This suggests that the exposure to these microplastic particles changes the physiological function of the tracheal tissues, specifically the control of air flow into the lungs. This exaggeration effect corresponds to the overactivation of muscarinic receptors in respiratory conditions such as chronic obstructive pulmonary disease (COPD) and asthma which results in bronchoconstriction and over-secretion of mucus (Buels \& Fryer, 2012).

During the experiments, these polyethylene microplastics tended to adhere to the tissues. However, at the highest concentration tested $(10 \mathrm{mg} / \mathrm{ml})$, they coalesced and formed tiny clusters in the buffer solution, reducing the adhesion to the tissues. This is one reason that the concentration of the sample was not increased above 10 $\mathrm{mg} / \mathrm{ml}$. It also provides a possible explanation for a lower response observed in $10 \mathrm{mg} / \mathrm{ml}$ compared to $5 \mathrm{mg} / \mathrm{ml}$. Adhesion of these polyethylene particles to the airway tissues seemingly mirrors the deposition of airborne particulate matter in these tissues.

As the airway epithelium is the principal deposition site for airborne particulate matter (Cooper \& Loxham, 2019), we postulated that the exposure to these microplastics damages the integrity of the epithelium. This notion can be supported by the findings of previous studies where removal of the epithelial lining of the airway smooth muscles enhanced acetylcholine- and histamine-induced contractions due to the loss of epithelium-derived relaxant factors such as nitric oxide, prostaglandins and adenosine triphosphate (Ruan et al., 2011). Furthermore, a recent study showed that following exposure to polystyrene microplastics (10 to $1000 \mu \mathrm{g} / \mathrm{cm} 2$ ), the expression of the tight junction proteins including Zonula Occludens, on the human lung epithelial cells was decreased, indicating a disruption to the lung epithelial lining (Dong et al., 2020).

The findings of this study contribute to evidence of the potential adverse effects of microplastic particles on the respiratory system. Nevertheless, some limitations of this study are acknowledged. Firstly, the primary microplastics (originated from the manufacturer) used may not accurately represent microplastics in the environment which may have interacted with chemical or biological pollutants, altering their properties and effects. However, using virgin polyethylene particle as our experimental sample gives the confident of the integrity of the sample. Secondly, the use of isolated tissues disregards the activation of innate defence mechanisms in vivo. An in vitro isolated tissue set up was employed because it can provide a direct evidence of changes to the physiological function following exposure to the microplastics. Nonetheless, further experiments involving isolation of microplastics from consumer goods such as face masks are being planned to enhance our understanding on the effect of microplastics. Histological investigation is also required to confirm the possible damaging effect of microplastics deposition on the integrity of the epithelial lining of tracheal tissue.

\section{CONCLUSION}

To the best of our knowledge, this is the first functional study to demonstrate the direct effect of microplastics on airway smooth muscle contractility. Our results show that exposure to microplastics significantly enhanced the contractile response of rat isolated airway smooth muscle. One plausible reason for this is damage to the epithelial lining. The results reported herein support various published hypotheses related to adverse effects following exposure to microplastics through inhalation. Further work including mechanistic studies and 
histological investigation as aforementioned are in the progress to delineate these initial findings.

\section{AUTHOR CONTRIBUTIONS}

Nurshafida Adzlin Shamsul Anuar and Li-Yin Pang performed the experiments and wrote the manuscript; Sivathass Bannir Selvam involved in preparation of the polyethylene microplastics; Christopher Gibbins supported the research and edited the manuscript. Kang-Nee Ting supported, designed, supervised, wrote and reviewed the manuscript. All authors read and approved the final manuscript.

\section{ETHICS APPROVAL}

Ethical approval was obtained from the University of Nottingham's Animal Welfare and Ethics Review Body (AWERB) (Reference: UNMC12).

\section{FUNDING}

The authors received no financial support for this research, authorship and publication of this article.

\section{CONFLICT OF INTEREST}

The authors declare no conflicts of interest in this work.

\section{ACKNOWLEDGEMENT}

We would like to thank Mr. Wong Siak Chung and Mr. Ahmad Fareez Mohd Rawi from the Faculty of Science and Engineering, University of Nottingham Malaysia for their valuable advice in the early stage of this work. We would also like to express our sincere gratitude to Sinowaja (Malaysia) Sdn. Bhd. for providing the high-density polyethylene pellets as a gift. Miss Li-Yin Pang receives a scholarship for her PhD studies from the University of Nottingham Malaysia.

\section{REFERENCES}

Adyel, T. M. (2020). Accumulation of plastic waste during COVID-19. Science, 369(6509), 1314-1315. https://doi.org/10.1126/science.abd9925

Amato-Lourenço, L. F., dos Santos Galvão, L., de Weger, L. A., Hiemstra, P. S., Vijver, M. G., \& Mauad, T. (2020). An emerging class of air pollutants: Potential effects of microplastics to respiratory human health? Science of the Total Environment, 749 (2020), 141676. https://doi.org/10.1016/j.scitotenv.2020.141676

Brahney, J., Mahowald, N., Prank, M., Cornwell, G., Klimont, Z., Matsui, H., \& Prather, K. A. (2021). Constraining the atmospheric limb of the plastic cycle. Proceedings of the National Academy of Sciences, 118(16), e2020719118. https://doi.org/10.1073/pnas.2020719118

Buels, K. S., \& Fryer, A. D. (2012). Muscarinic receptor antagonists: Effects on pulmonary function. Handbook of Experimental Pharmacology 208, 317-341. https://doi.org/10.1007/978-3-642-23274-9_14

Bustamante-Marin, X. M., \& Ostrowski, L. E. (2017). Cilia and mucociliary clearance. Cold Spring Harbor Perspectives in Biology, $9(4)$. https://doi.org/10.1101/cshperspect.a028241

Cooper, D. M., \& Loxham, M. (2019). Particulate matter and the airway epithelium: The special case of the underground? European Respiratory Review, 28(153), 1-10. https://doi.org/10.1183/16000617.0066-2019

Dong, C. di, Chen, C. W., Chen, Y. C., Chen, H. H., Lee, J. S., \& Lin, C. H. (2020). Polystyrene microplastic particles: In vitro pulmonary toxicity assessment. Journal of Hazardous Materials, 385(2020), 121575. https://doi.org/10.1016/i.jhazmat.2019.121575

Fadare, O. O., \& Okoffo, E. D. (2020). Covid-19 face masks: A potential source of microplastic fibers in the environment. Science of the Total Environment, 737(2020), 140279. https://doi.org/10.1016/i.scitotenv.2020.140279

Frias, J. P. G. L., \& Nash, R. (2019). Microplastics: Finding a consensus on the definition. Marine Pollution Bulletin, 138 (2019), 145-147. https://doi.org/10.1016/i.marpolbul.2018.11.022 
Geiser, M., \& Kreyling, W. G. (2010). Deposition and biokinetics of inhaled nanoparticles. Particle and Fibre Toxicology $7(2010), 2$. https://doi.org/10.1186/1743-8977-7-2

Honeycutt, J. A., Nguyen, J. Q. T., Kentner, A. C., \& Brenhouse, H. C. (2017). Effects of water bottle materials and filtration on bisphenol A content in laboratory animal drinking water. Journal of the American Association for Laboratory Animal Science, $56(3), 269-272$.

https://pubmed.ncbi.nlm.nih.gov/28535862/

Li, L., Zhao, X., Li, Z., \& Song, K. (2021). COVID-19: Performance study of microplastic inhalation risk posed by wearing masks. Journal of Hazardous Materials, 411(2021), 124955. https://doi.org/10.1016/i.jhazmat.2020.124955

Loong, B. J., Tan, J. H., Lim, K. H., Mbaki, Y., \& Ting, K. N. (2015). Contractile function of smooth muscle retained after overnight storage. Naunyn-Schmiedeberg's Archives of Pharmacology, 388(10), 1061-1067. https://doi.org/10.1007/s00210-015-1140-3

Pang, L.Y., Sonagara, S., Oduwole, O., Gibbins, C., \& Ting, K.N. (2021). Microplastics - an emerging silent menace to public health. Life Sciences, Medicine and Biomedicine, 5(10). https://doi.org/10.28916/lsmb.5.1.2021.72

Prata, J. C. (2018). Airborne microplastics: Consequences to human health? Environmental Pollution, 234(2018), 115-126. https://doi.org/10.1016/i.envpol.2017.11.043

Prata, J. C., da Costa, J. P., Lopes, I., Duarte, A. C., \& Rocha-Santos, T. (2020). Environmental exposure to microplastics: An overview on possible human health effects. Science of the Total Environment, 702(2020), 134455. https://doi.org/10.1016/i.scitotenv.2019.134455

Ruan, Y. C., Zhou, W., \& Chan, H. C. (2011). Regulation of smooth muscle contraction by the epithelium: role of prostaglandins. Physiology, 26(3), 156-170. https://doi.org/10.1152/physiol.00036.2010

Thomas, R. J. (2013). Particle size and pathogenicity in the respiratory tract. Virulence 4(8), 847-858. https://doi.org/10.4161/viru.27172

Vianello, A., Jensen, R. L., Liu, L., \& Vollertsen, J. (2019). Simulating human exposure to indoor airborne microplastics using a Breathing Thermal Manikin. Scientific Reports, 9(1), 1-11. https://doi.org/10.1038/s41598-019-45054-w

Wright, S. L., Ulke, J., Font, A., Chan, K. L. A., \& Kelly, F. J. (2020). Atmospheric microplastic deposition in an urban environment and an evaluation of transport. Environment International, 136(2020), 105411. https://doi.org/10.1016/j.envint.2019.105411

Zhang, Y., Kang, S., Allen, S., Allen, D., Gao, T., \& Sillanpää, M. (2020). Atmospheric microplastics: A review on current status and perspectives. In Earth-Science Reviews, 203(2020), 103118 https://doi.org/10.1016/j.earscirev.2020.103118

\section{Citation:}

Kang Nee, T., Shamsul Anuar, N. A., Pang, L.-Y., Selvam, S. B., \& Gibbins, C. N. (2022). Polyethylene microplastics adversely affect airway patency. Life Sciences, Medicine and Biomedicine, 6(1).

https://doi.org/10.28916/lsmb.6.1.2022.93

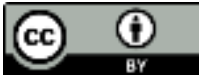

Life Sciences, Medicine and Biomedicine ISSN: 2600-7207

Copyright (C) 2022 by the Author(s). Life Sciences, Medicine and Biomedicine (ISSN: 2600-7207) Published by Biome Journals - Biome Scientia Sdn Bhd. Attribution 4.0 International (CC BY 4.0). This open access article is distributed based on the terms and conditions of the Creative Commons Attribution license https://creativecommons.org/licenses/by/4.0/ 